\title{
Local structure of the magnetotail current sheet: 2001 Cluster observations
}

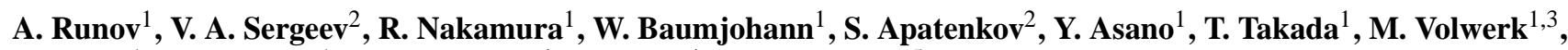 \\ Z. Vörös ${ }^{1}$, T. L. Zhang ${ }^{1}$, J.-A. Sauvaud ${ }^{4}$, H. Rème ${ }^{4}$, and A. Balogh \\ ${ }^{1}$ Space Research Institute, Austrian Academy of Sciences, A-8042 Graz, Austria \\ ${ }^{2}$ St. Petersburg University, St. Petersburg, Russia \\ ${ }^{3}$ MPE, Garching, Germany \\ ${ }^{4}$ CESR/CNRS, Toulouse, France \\ ${ }^{5} \mathrm{IC}$, London, UK
}

Received: 11 August 2005 - Revised: 8 November 2005 - Accepted: 15 November 2005 - Published: 7 March 2006

\begin{abstract}
Thirty rapid crossings of the magnetotail current sheet by the Cluster spacecraft during July-October 2001 at a geocentric distance of $19 R_{E}$ are examined in detail to address the structure of the current sheet. We use four-point magnetic field measurements to estimate electric current density; the current sheet spatial scale is estimated by integration of the translation velocity calculated from the magnetic field temporal and spatial derivatives. The local normalrelated coordinate system for each case is defined by the combining Minimum Variance Analysis (MVA) and the curlometer technique. Numerical parameters characterizing the plasma sheet conditions for these crossings are provided to facilitate future comparisons with theoretical models. Three types of current sheet distributions are distinguished: centerpeaked (type I), bifurcated (type II) and asymmetric (type III) sheets. Comparison to plasma parameter distributions show that practically all cases display non-Harris-type behavior, i.e. interior current peaks are embedded into a thicker plasma sheet. The asymmetric sheets with an off-equatorial current density peak most likely have a transient nature. The ion contribution to the electric current rarely agrees with the current computed using the curlometer technique, indicating that either the electron contribution to the current is strong and variable, or the current density is spatially or temporally structured.
\end{abstract}

Keywords. Magnetospheric physics (Magnetotail, Plasma sheet)

\section{Introduction}

Current sheet structure is an important property of plasma boundaries, which determines their stability against perturbations and explosive disruptions. This characteristic is,

Correspondence to: A. Runov

(andrei.runov@oeaw.ac.at) however, very difficult to measure in space; so in previous years the theory was mostly based on a signal, simple, 1-D solution, known as Harris sheet (after Harris, 1962). Its basic property is that both current and plasma density vary across the sheet as $\cosh ^{-2}(z / L)$, whereas the sheet is considered to be isothermal (with $T_{e}=T_{i}$ ) and with equal contributions from protons and electrons to the electric current. In the last century, the overwhelming majority of theoretical analysis was done using the Harris-type sheet models. At the same time the information about the different structure of real tail current sheets was slowly accumulated.

Flapping motion of the magnetotail current sheet manifests itself as both large-amplitude (a few tens of nT) and short duration (tens of seconds to several minutes), often repeating variations of the magnetic field main component, observed by spacecraft in the plasma sheet. Being an interesting phenomenon itself, the flapping provides a tool to probe the internal structure of the current sheet. A number of past studies addressed the problem of current sheet internal structure based on observations from single or dual (ISEE-1/2) spacecraft, and different techniques have been suggested to characterize the current sheet scale and structure. Fairfield et al. (1981) tried the ion gyroradius technique and interpreted a set of very rapid (with durations of 10-60 s) neutral sheet crossings by the IMP-8 spacecraft at $\mathrm{X}=-32 R_{E}$ as a wave propagating in the sunward-anti-sunward direction. They estimated the current sheet flapping velocity to be $100-300 \mathrm{~km} / \mathrm{s}$ and the apparent current sheet thickness to be $h \sim 1000-2000 \mathrm{~km}$.

McComas et al. (1986) analyzed three crossings of the magnetotail current sheet by ISEE $1 / 2$ (separation of a few thousands $\mathrm{km}$ ) at $20 R_{E}$, which were probably due to bulk tail motion caused by an interplanetary shock. From twopoint timing and MVA results they estimated the current sheet normal velocity, and then derived the current density as a ratio of $\Delta B_{l}$ and $V_{n} \Delta t$, where $l$ is a unit vector along the reversed magnetic field direction (maximum variation) 
and $V_{n}$ is the normal velocity of the current sheet, calculated as a function of time. The profiles of the electric current density versus distance from the sheet center (where $\left.B_{l}=0\right)$ showed a very thick sheet $(h \leq 10000 \mathrm{~km})$ with low current density $\left(j \sim 4 \mathrm{nA} / \mathrm{m}^{2}\right)$ for the first crossing, a much thinner and more intensive $\left(h \sim 2500 \mathrm{~km}\right.$ and $\left.j \sim 15 \mathrm{nA} / \mathrm{m}^{2}\right)$ sheet with a slightly asymmetric maximum and "shoulders" of a weaker current density for the second case, and an extremely strong $\left(j \sim 50 \mathrm{nA} / \mathrm{m}^{2}\right)$ current sheet with a half-thickness of $3000 \mathrm{~km}$ for the third case. The structures were not uniform and show embedded layers with scales of $1000 \mathrm{~km}$.

Sergeev et al. (1993) analyzed 10 neutral sheet crossings by the ISEE $1 / 2$ spacecraft (estimated separation about $470 \mathrm{~km}$ across the current sheet) at $X \sim-11 R_{E}$ during a substorm. Considering the $B_{x}$ difference between the two spacecraft (as a measure of current density) against the average $B_{x}$ (as measure of the position in the sheet), different types of current sheet distributions were found. They included current peaks embedded in the sheet center (during the substorm growth phase), a distinct example of a thin bifurcated current sheet during fast plasma flow (presumably near the reconnection site), as well as examples of turbulent and transientdominated distributions. The estimated current sheet halfthickness $h$ varied between $650 \mathrm{~km}(\sim 2$ gyroradii of $10 \mathrm{keV}$ proton in the lobe field, detected prior to the current disruption) and $\sim 4000 \mathrm{~km}$ or $\sim 12$ external gyroradii.

Using another method, fitting ISEE $1 / 2$ magnetic field data to the Harris function, Sanny et al. (1994) inferred that the current sheet thickness at $\mathrm{X} \sim-13 R_{E}$ varied from several $R_{E}$ at the beginning of the substorm growth phase to $h \sim 0.1 R_{E}$ just after expansion onset. They also suggested a multi-point calculation approach, based on calculations of the convective derivative, which allows one to reconstruct an effective vertical scale of the current sheet during its crossing by a group of spacecraft.

An alternative technique to estimate the thickness of a flapping current sheet using ion bulk velocity measurements has been suggested in Sergeev et al. (1998). If the up/down motions of the current sheet are seen as positive/negative variations of the bulk velocity $Z$-component, the current sheet scale $h$ can be estimated from the linear regression slope between $V_{Z}$ and $\partial_{t} B_{x}$. For a set of current sheet crossings by the AMPTE/IRM spacecraft at $R \sim 12-18 R_{E}$, they found the sheet scales varying from $\sim 2$ to $0.2 R_{E}$ and electric current densities from 4 to $30 \mathrm{nA} / \mathrm{m}^{2}$.

Analyzing the $B_{x}$-occurrence frequency distribution during multiple current sheet crossings (expected to be inversely proportional to $d B_{x} / d z$ gradients in the case of vertical flapping motions), measured by the Geotail spacecraft at $\sim 100 R_{E}$ in the tail, Hoshino et al. (1996) found distributions consistent with a double-peaked (bifurcated) current density profile. Because such structures were observed during fast ion flows, Hoshino et al. (1996) attributed them to slow shock structures downstream of a reconnection site. Later, Asano et al. (2003), using electron and ion moments from Geotail to calculate the electric current density, inferred similar doublepeak structures at a distance of $15 R_{E}$ downtail. They argued that such structures appear as a local or/and temporal enhancement of the current density away from the neutral sheet, associated with current sheet thinning and flapping prior to substorm onset. In that case the current sheet bifurcation may not be associated with magnetic reconnection.

Greatly enhanced possibilities of measuring spatial gradients have appeared after the launch of the four-spacecraft Cluster system, whose early results showed a number of examples of complex behavior and structure of the tail current sheet. The fast dynamics of the current sheet structure was demonstrated by Nakamura et al. (2002), providing the example of rapid change from the Harris type to the bifurcated shape during a fast earthward flow event, and by Runov et al. (2005b), who documented the opposite change during substorm expansion. Distinct examples of stable (during 10-15 min intervals) bifurcated distributions during substorm times have been provided by Runov et al. (2003b) and Sergeev et al. (2003). The need for careful determination of a proper coordinate system follows from statistical studies by Sergeev et al. (2004) and Runov et al. (2005a), who showed that flapping current sheets are unusually strongly tilted in the $Y-Z$ plane. Moreover, Asano et al. (2005) and Runov et al. (2005a) found that off-center peak distributions of the current density seem to be a frequent property of the current sheet.

As seen from this Introduction, the rapidly growing evidence of different possible current distributions requires one to perform a systematic study of the current sheet structure using all Cluster possibilities, to infer the current density distribution in the proper coordinate system. This will be the purpose of our paper, in which, as a continuation of the previous publication (Runov et al., 2005a), we investigate the profiles of the current density and ion moments during carefully selected rapid crossings of the current sheet. We focus on the current structure and also provide the lists of quantitative current sheet characteristics, which may be useful for further comparison with theoretical models.

The 1-s averaged magnetic field data from the Cluster Flux Gate Magnetometer (FGM, Balogh et al., 2001) and 2-spin (normal mode) or 1-spin (burst mode) averaged data from the Cluster Ion Spectrometry experiment (CIS, Rème et al., 2001) are used in the analysis presented in this paper.

\section{Selection of events and local coordinate system}

The basic criteria for selection of the rapid current sheet crossings are discussed in our previous paper (Runov et al., 2005a). They are (i) the change in the magnetic field $X$-component at the Cluster tetrahedron barycenter larger than $15 \mathrm{nT}$, during a time less than 5-min, with a change in the $B_{x}$ sign, indicating the neutral sheet crossing; (ii) the current sheet is stable during the crossing (in a sense that magnetogram shapes are similar at four spacecraft); and (iii) the ratio of the magnetic field divergence and curl is less than 0.25 for more than $60 \%$ of samples during the crossing. We 
Table 1. Selected events.

\begin{tabular}{|c|c|c|c|c|c|c|c|c|c|c|c|c|c|}
\hline $\mathrm{N}$ & date $^{\mathrm{a}}$ & $t_{0}{ }^{\mathrm{b}}(\mathrm{UT})$ & $\operatorname{IMF}_{y}{ }^{\mathrm{c}}$ & $\mathrm{IMF}_{z}{ }^{\mathrm{c}}$ & $A E^{\mathrm{d}}$ & $Y^{\mathrm{e}}, R_{E}$ & $N_{i}{ }^{\mathrm{f}}, \mathrm{cm}^{-3}$ & $V_{x}^{\mathrm{f}}$ & $V_{y}{ }^{\mathrm{f}}$ & $V_{z}{ }^{\mathrm{f}}, \mathrm{km} / \mathrm{s}$ & $T_{i}{ }^{\mathrm{f}}, \mathrm{keV}$ & $\mathrm{PO} / \mathrm{PH}^{\mathrm{g}}$ & $B_{L}{ }^{\mathrm{h}}, \mathrm{nT}$ \\
\hline 1 & 0724 & $17: 18: 53$ & -8.2 & 0.9 & 439 & -13.0 & 0.66 & 25 & -15 & 27 & 6.0 & 0.05 & 36.8 \\
\hline 2 & 0724 & $17: 44: 55$ & -7.0 & 1.5 & 428 & -13.0 & 0.62 & 47 & 3 & -28 & 6.0 & 0.07 & 35.3 \\
\hline 3 & 0727 & $10: 39: 17$ & -0.6 & 0.4 & 169 & -11.0 & 0.29 & -38 & -2 & -75 & 8.1 & 0.04 & 26.1 \\
\hline 4 & 0803 & 09:17:34 & -8.4 & -3.3 & 213 & -9.7 & 0.60 & 93 & 2 & -117 & 8.0 & 0.05 & 39.8 \\
\hline 5 & 0812 & $15: 28: 06$ & -7.5 & -6.8 & 166 & -7.3 & 1.77 & 17 & 16 & -33 & 2.1 & 0.05 & 37.9 \\
\hline 6 & 0812 & $15: 29: 45$ & -7.5 & -6.8 & 166 & -7.3 & 1.71 & 2 & 16 & 52 & 2.3 & 0.04 & 37.6 \\
\hline 7 & 0822 & 08:57:41 & -0.6 & 2.4 & 118 & -4.6 & 0.39 & 75 & -10 & 49 & 6.4 & 0.05 & 27.4 \\
\hline 8 & 0910 & 08:03:32 & 1.0 & -0.5 & 69 & 0.8 & 0.69 & 10 & -10 & -25 & 1.5 & 0.04 & 21.0 \\
\hline 9 & 0910 & $08: 12: 15$ & 1.1 & -0.5 & 59 & 0.8 & 0.73 & 0 & -19 & -28 & 1.2 & 0.03 & 20.2 \\
\hline 10 & 0912 & 14:19:03 & 6.7 & -2.5 & 288 & 1.7 & 0.40 & 14 & -12 & -8 & 4.6 & 0.14 & 25.7 \\
\hline 11 & 0912 & $14: 22: 45$ & 6.7 & -1.8 & 292 & 1.6 & 0.42 & 112 & -4 & 7 & 5.1 & 0.16 & 26.6 \\
\hline 12 & 0914 & $22: 55: 00$ & -4.9 & -4.6 & 119 & 2.0 & 2.30 & 37 & -57 & 0 & 1.0 & 0.08 & 32.6 \\
\hline 13 & 0914 & $23: 10: 03$ & -3.5 & -8.8 & 193 & 2.0 & 2.43 & -28 & -63 & -66 & 1.1 & 0.09 & 33.4 \\
\hline 14 & 0914 & 23:50:06 & -5.0 & -4.3 & 250 & 2.1 & 3.17 & 17 & -32 & -28 & 1.4 & 0.12 & 42.6 \\
\hline 15 & 0924 & 08:04:20 & -4.3 & 5.6 & 23 & 5.0 & 0.87 & 0 & -32 & -45 & 2.6 & 0.42 & 30.1 \\
\hline 16 & 0924 & 08:07:58 & -5.3 & 4.5 & 22 & 5.0 & 0.86 & 29 & -26 & -10 & 2.4 & 0.43 & 30.0 \\
\hline 17 & 0926 & $22: 26: 27$ & -0.7 & 0.3 & 139 & 5.9 & 1.09 & -22 & 34 & -25 & 2.1 & 0.19 & 27.5 \\
\hline 18 & 0926 & $22: 27: 24$ & -0.7 & 0.3 & 140 & 5.9 & 1.15 & -3 & 5 & -63 & 2.0 & 0.17 & 28.3 \\
\hline 19 & 1001 & $09: 42: 45$ & 10.0 & -1.1 & 625 & 6.8 & 0.24 & 17 & -17 & 5 & 4.8 & 0.49 & 31.9 \\
\hline 20 & 1001 & 09:50:06 & 9.9 & -0.5 & 627 & 6.8 & 0.13 & 538 & -277 & -260 & 4.1 & 7.21 & 20.7 \\
\hline 21 & 1008 & $12: 30: 43$ & 6.3 & 2.5 & 286 & 8.4 & 0.57 & -28 & 18 & -4 & 6.8 & 0.20 & 36.2 \\
\hline 22 & 1008 & $12: 49: 16$ & 6.9 & 1.6 & 326 & 8.5 & 0.44 & 22 & -43 & -12 & 4.3 & 0.25 & 32.9 \\
\hline 23 & 1008 & $13: 00: 21$ & 7.2 & 0.6 & 366 & 8.5 & 0.36 & 59 & -47 & -8 & 5.5 & 0.44 & 33.0 \\
\hline 24 & 1008 & 13:06:50 & 7.4 & 1.2 & 400 & 8.5 & 0.16 & 10 & -19 & -39 & 7.0 & 0.48 & 26.2 \\
\hline 25 & 1013 & 08:07:39 & -4.6 & -1.2 & 227 & 9.7 & 0.33 & 172 & -19 & -18 & 6.9 & 0.19 & 25.9 \\
\hline 26 & 1020 & 09:28:21 & 5.5 & -2.1 & 208 & 11.0 & 0.69 & 71 & -29 & -25 & 4.5 & 0.27 & 32.5 \\
\hline 27 & 1020 & 09:38:05 & 3.9 & -2.5 & 238 & 11.0 & 0.60 & 10 & 7 & -33 & 3.5 & 0.32 & 32.0 \\
\hline 28 & 1020 & $09: 46: 55$ & 3.1 & -4.1 & 240 & 11.0 & 0.61 & 11 & 45 & 3 & 3.2 & 0.38 & 28.4 \\
\hline 29 & 1020 & 09:57:12 & 2.9 & -4.7 & 234 & 11.1 & 0.57 & 4 & 13 & -14 & 3.1 & 0.39 & 26.8 \\
\hline 30 & 1020 & 09:58:57 & 3.1 & -4.8 & 232 & 11.1 & 0.63 & -6 & -16 & 1 & 3.2 & 0.34 & 25.9 \\
\hline
\end{tabular}

a) date format: mmdd of 2001 ;

b) the instance of $\left|B_{x b c}\right|=\min \left(\left|B_{x b c}\right|\right)$;

c) 16-min averaged IMF $y$ - and $z$-components from ACE spacecraft at the shifted $t_{0}$;

d) 2-h averaged $A E$ at $t_{0}$ from the Kyoto monitor;

e) the $Y_{A G S M}$ coordinate of the Cluster barycenter at $t_{0}$;

f) the average ion density, components of the bulk velocity and temperature during the crossing (Cluster 1 and 4 CODIF data within $\left.\left|B_{x}\right| \leq 0.5 B_{L}\right)$;

g) the average $\mathrm{O}^{+}$and $\mathrm{H}^{+}$pressures ratio during the crossing (Cluster 1 and 4 CODIF data within $\left|B_{x}\right| \leq 0.5 B_{L}$ );

h) the asymptotic magnetic field value in the lobe, estimated from pressure balance: $\left.B_{L}=\left(B^{2}+2 \mu_{0} P_{i}\right)^{1 / 2}, P_{i}=P_{\mathrm{H}^{+}}+P_{\mathrm{O}^{+}}\right)$, the electron pressure is not included.

selected 78 events of the neutral sheet crossing, according to these selection criteria.

To make an investigation of the current sheet structure possible, we visually analyzed the calculated magnetic field gradient $\nabla B_{l}$ (where $l$ is the maximum variance eigenvector resulting from the MVA applied for the magnetic field time series at the Cluster barycenter), to find cases with smooth, monotonous profiles of $\nabla B_{l}$ versus $B_{l}$, for which the structure may be defined. Comparing $\nabla_{n} B_{l}$, where $\nabla_{n}$ is the component of the gradient along the local normal to the current sheet (see the definition below), and $\left|\nabla B_{l}\right|$ profiles, we selected cases with a minimum change inf the current sheet orientation during flapping (when both curves do not deviate much from each other). Finally, we have chosen 30 profiles (which is a compromise number to be representative enough and possible to visualize) which were most suitable for the spatial profile reconstruction crossings covering large portions of the current sheet on both the northern and southern halves, for further analysis.

Table 1 presents the dates and UT of the selected crossings, the 16-min average values of IMF $Y$ - and $Z$-components (in $\mathrm{nT}$ ) from the ACE spacecraft around time shifted $t_{0}$; values of the auroral electrojet index (in nT, averaged during an interval of \pm 60 -min around the barycenter crossing time $t_{0} ; Y_{A G S M}$ coordinates of Cluster; average ion density $N_{i}$ ( $\mathrm{H}^{+}$and $\mathrm{O}^{+}$species); temperature $T_{i}\left(\mathrm{H}^{+}\right.$only); ion velocity 
Table 2. Local normal coordinate system ${ }^{\mathrm{a}}$.

\begin{tabular}{|c|c|c|c|c|c|c|c|c|c|c|}
\hline $\mathrm{N}$ & $L_{x}$ & $L_{y}$ & $L_{z}$ & $M_{x}$ & $M_{y}$ & $M_{z}$ & $N_{x}$ & $N_{y}$ & $N_{z}$ & $\mathbf{n} \cdot \mathbf{n}_{t}$ \\
\hline 1 & 0.828 & 0.561 & -0.009 & -0.034 & 0.073 & 0.991 & 0.557 & -0.820 & 0.079 & 0.988 \\
\hline 2 & 0.767 & 0.615 & -0.180 & -0.567 & 0.521 & -0.637 & -0.299 & 0.591 & 0.749 & 0.998 \\
\hline 3 & 0.872 & 0.478 & 0.102 & -0.446 & 0.856 & -0.231 & -0.198 & 0.156 & 0.959 & 0.983 \\
\hline 4 & 0.920 & 0.319 & -0.229 & -0.341 & 0.361 & -0.868 & -0.194 & 0.877 & 0.440 & 0.995 \\
\hline 5 & 0.975 & 0.020 & -0.222 & 0.187 & 0.476 & 0.861 & 0.123 & -0.881 & 0.460 & 0.907 \\
\hline 6 & 0.926 & 0.131 & -0.353 & -0.372 & 0.170 & -0.908 & -0.059 & 0.973 & 0.206 & 0.988 \\
\hline 7 & 0.985 & 0.149 & -0.086 & -0.167 & 0.948 & -0.270 & 0.041 & 0.280 & 0.959 & 1.000 \\
\hline 8 & 0.994 & -0.103 & 0.036 & 0.024 & 0.531 & 0.847 & -0.106 & -0.841 & 0.531 & 0.99 \\
\hline 9 & 0.999 & -0.048 & 0.016 & 0.029 & 0.801 & 0.597 & -0.041 & -0.596 & 0.802 & 0.901 \\
\hline 10 & 0.991 & 0.094 & 0.091 & -0.084 & 0.991 & -0.108 & -0.100 & 0.100 & 0.990 & 0.998 \\
\hline 11 & 0.998 & 0.025 & 0.057 & -0.032 & 0.990 & 0.132 & -0.054 & -0.133 & 0.989 & 0.999 \\
\hline 12 & 0.978 & -0.113 & -0.176 & 0.176 & -0.013 & 0.974 & -0.112 & -0.983 & 0.007 & 0.971 \\
\hline 13 & 0.970 & -0.141 & -0.200 & 0.240 & 0.389 & 0.889 & -0.047 & -0.910 & 0.411 & 0.941 \\
\hline 14 & 0.997 & -0.037 & -0.067 & -0.003 & 0.858 & -0.514 & 0.076 & 0.513 & 0.855 & 0.964 \\
\hline 15 & 0.992 & 0.006 & -0.127 & -0.125 & -0.046 & -0.968 & -0.011 & 0.976 & -0.045 & 0.919 \\
\hline 16 & 0.990 & -0.023 & -0.141 & 0.141 & 0.339 & 0.939 & 0.026 & -0.949 & 0.338 & 1.000 \\
\hline 17 & 0.986 & -0.164 & 0.029 & 0.135 & 0.682 & -0.719 & 0.098 & 0.713 & 0.694 & 0.888 \\
\hline 18 & 0.948 & -0.266 & 0.178 & -0.026 & 0.489 & 0.892 & -0.324 & -0.850 & 0.457 & 1.000 \\
\hline 19 & 0.988 & -0.125 & -0.085 & 0.107 & 0.976 & -0.191 & 0.107 & 0.180 & 0.978 & 0.998 \\
\hline 20 & 0.950 & 0.308 & -0.044 & -0.302 & 0.946 & 0.117 & 0.078 & -0.098 & 0.992 & 0.988 \\
\hline 21 & 0.928 & -0.323 & 0.185 & -0.039 & 0.410 & 0.911 & -0.370 & -0.853 & 0.368 & 0.962 \\
\hline 22 & 0.988 & -0.072 & -0.136 & -0.014 & 0.836 & -0.548 & 0.153 & 0.544 & 0.825 & 0.903 \\
\hline 23 & 0.996 & -0.036 & -0.086 & 0.079 & 0.827 & 0.562 & 0.051 & -0.567 & 0.826 & 0.958 \\
\hline 24 & 0.973 & -0.197 & 0.120 & 0.193 & 0.979 & 0.047 & -0.127 & -0.022 & 0.990 & 0.894 \\
\hline 25 & 0.977 & -0.209 & -0.042 & 0.034 & -0.041 & 0.989 & -0.209 & -0.967 & -0.033 & 0.953 \\
\hline 26 & 0.970 & -0.216 & -0.108 & 0.120 & 0.819 & -0.560 & 0.210 & 0.531 & 0.821 & 0.999 \\
\hline 27 & 0.921 & -0.379 & 0.088 & 0.012 & 0.254 & 0.967 & -0.389 & -0.890 & 0.238 & 0.999 \\
\hline 28 & 0.900 & -0.436 & -0.016 & 0.117 & 0.206 & 0.973 & -0.421 & -0.877 & 0.237 & 0.999 \\
\hline 29 & 0.955 & -0.290 & 0.071 & 0.229 & 0.864 & 0.452 & -0.192 & -0.415 & 0.891 & 0.998 \\
\hline 30 & 0.944 & -0.309 & 0.113 & 0.115 & -0.011 & -0.989 & 0.307 & 0.947 & 0.025 & 0.946 \\
\hline
\end{tabular}

a) GSM components of local normal coordinate system with the quality check (see explanations in the text).

$V_{x, y, z}\left(\mathrm{H}^{+}\right.$only), the ratio of proton and $O^{+}$ions pressures and average lobe magnetic field $B_{L}=\left(B^{2}+2 \mu_{0} P_{i}\right)^{1 / 2}$. The density, temperature, velocity and pressure are averaged over $B_{x} \leq 0.5 B_{L}$ samples using Cluster 1 and 4 CODIF data.

For each selected crossing the local normal coordinate system $\boldsymbol{l}, \boldsymbol{m}, \boldsymbol{n}$ was defined. As usual, the $\boldsymbol{l}$ axis is directed along the maximum variance eigenvector (from MVA, applied to the magnetic field at the barycenter, $\boldsymbol{B}_{b c}$ ). The $\boldsymbol{m}$-axis is aligned along the component of the electric current $\boldsymbol{j}=\mu_{0}^{-1} \nabla \times \boldsymbol{B}$ perpendicular to $\boldsymbol{l}$, averaged over the neutral sheet $\left(\left|B_{x}\right|<5 \mathrm{nT}\right): \boldsymbol{m}=\boldsymbol{l} \times[\boldsymbol{j} / j \times \boldsymbol{l}]$. Finally, the $\boldsymbol{n}$-axis is directed perpendicular to $\boldsymbol{l}$ and $\boldsymbol{m}: \boldsymbol{n}=\boldsymbol{l} \times \boldsymbol{m}$. Components of the local orthogonal coordinate system $\boldsymbol{l}, \boldsymbol{m}, \boldsymbol{n}$ are given in Table 2. In 13 cases of of 30, the tilt angle of the normal $\phi=\operatorname{atan}\left(\left|n_{y}\right| /\left|n_{z}\right|\right)$ was larger than $60^{\circ}$ (the normal $\boldsymbol{n}$ is directed mainly along $Y_{G S M}$ ), in 9 cases $30^{\circ}<\phi<60^{\circ}$, and only in 8 cases $\phi<30^{\circ}$ (the normal has a nominal orientation along $Z_{G S M}$ ).

To check the quality of the local coordinate system, we compared the normal $\mathbf{n}$ with the normal vector $\mathbf{n}_{t}$, resulting from multi-point timing analysis (Harvey, 1998). The scalar products of two normals $\boldsymbol{n} \cdot \boldsymbol{n}_{t}$ are also presented in Table 2 . The angle between these two normals varies between 0 and $27^{\circ}$, with a median value $8.9^{\circ}$, confirming that the normals are very accurately defined in our set of current sheet crossings.

Figure 1 surveys the time series of $\boldsymbol{l}, \boldsymbol{m}, \boldsymbol{n}$ magnetic field components at the Cluster barycenter, $\boldsymbol{B}_{\mathrm{bc}}=0.25 \sum_{\alpha=1}^{4} \boldsymbol{B}_{\alpha}$, where $\alpha$ is a spacecraft number. The crossing duration $\tau$ varies from $35 \mathrm{~s}$ to $300 \mathrm{~s}$ with the 144-s median. In 12 cases the average normal component of the magnetic field in the sheet center (where $\left|B_{l}\right|<5 \mathrm{nT}$ ) is very small: $B_{n}<1 \mathrm{nT}$, and only in three cases is the mean value is large, about $5 \mathrm{nT}$. The most frequent value is $1.3 \mathrm{nT}$. The current-aligned component of magnetic field $B_{m}$ is typically larger (in the sheet center) than $B_{n}$, it varies in the wide range 0 to $0.3 B_{L}$ and its median value is $B_{m}$ is $3.5 \mathrm{nT}$.

\section{Current sheet structures}

To probe the structure of the current sheet during flapping and estimate its scale, we investigate a distribution of the cur- 

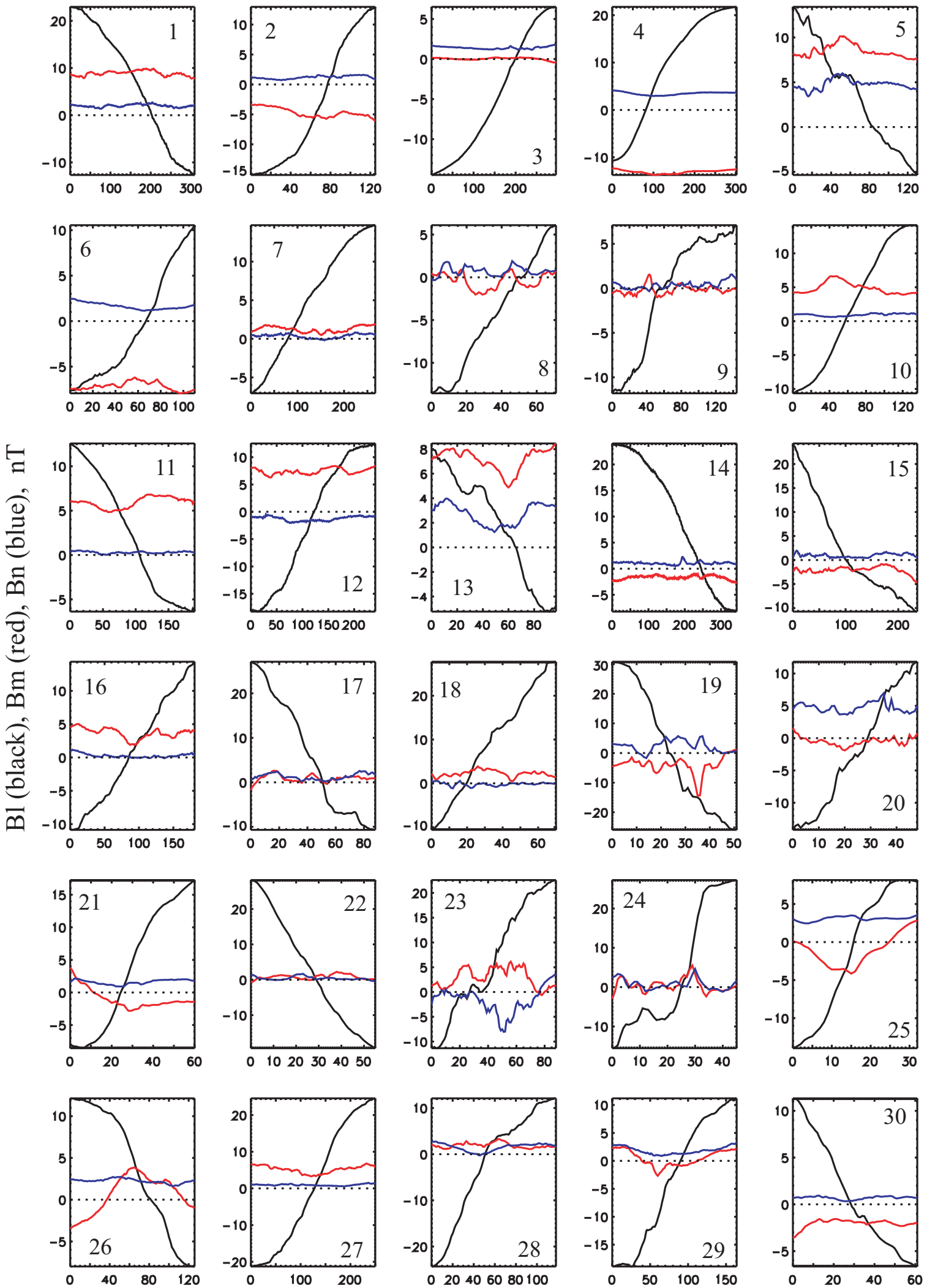

$\tau, \mathrm{S}$

Fig. 1. Time series of the magnetic field at the Cluster barycenter in local normal coordinate system $\{\boldsymbol{l}, \boldsymbol{m}, \boldsymbol{n}\}$ (see text for details) for 30 selected cases. $B_{l}$ : black, $B_{m}$ : red and $B_{n}$ : blue. 
rent density $\boldsymbol{j}=\mu_{0}^{-1} \nabla \times \boldsymbol{B}$, calculated using a linear curl estimator technique, based on the tetrahedron reciprocal vectors method (Chanteur, 1998).

Figure 2 presents profiles of the absolute value of the current density (red curves) and the perpendicular current $j_{\perp}=\left(j_{m}^{2}+j_{n}^{2}\right)^{1 / 2}$ (blue curves) versus $B_{l}$ at the Cluster barycenter, normalized by the average value of the magnetic field in the lobe $\left(B_{L}\right.$, see Table 1). Dashed curves show the profiles of the corresponding Harris current as a function of a variable $b=B_{l} / B_{L}$ running between -1 and 1 :

$j_{H}=\frac{B_{L}}{\mu_{0} \lambda}\left[1-b^{2}\right]$,

where the Harris scale $\lambda$ is defined for each crossing as the median of instantaneous values

$\lambda=\frac{B_{L}}{\left\langle\nabla_{n} B_{l}\right\rangle}\left[1-\left(\frac{B_{l}}{B_{L}}\right)^{2}\right]$.

To display scales of the observed structures we plot in Fig. 3 the profiles of the current density and the perpendicular current versus the effective vertical coordinate

$Z^{*}(t)=\int_{t_{1}}^{t} \frac{\partial B_{l}}{\partial t}\left[\nabla_{n} B_{l}\right]^{-1} d t^{\prime}-Z^{*}\left(t_{0}\right)$,

where $t_{1}$ and $t_{2}$ are instances of the beginning and the end of the crossing, respectively, and $t_{0}$ is the time of the neutral sheet crossing by the Cluster barycenter. (Details of the reconstruction procedure and its accuracy are discussed by Runov et al., 2005a.) For reference, as in Fig. 2, the dashed curves show the Harris current.

Observed current sheet structures can be subdivided into three classes: I - central sheets with single peak centered near $B_{l}=0$ (be most clear examples are \#4, 6, 10, 11, 12, 13, 21, 24, 26, 30); II - bifurcated sheets with two off-equatorial maxima of the current density and local minimum of the current density between them (\#14, 20, 22, 25, 27); and III asymmetric off-center current sheets with the current density maximum shifted from equatorial plane (\#5, 7, 15, 16, 17, $18,28,29)$. Figure 4 shows a summary of the current density distributions for most clear cases of these three classes, together with the average profile.

It is difficult to attribute undoubtedly cases \# 1, 2, 3, 8, 9 and 23 to the described types: they have a more or less central single peak but are asymmetric or slightly bifurcated like distributions of the current density as \# 2. The case \# 19 seems to be very peculiar. It was observed during a storm-time substorm on 1 October 2001 near the reconnection site (Runov et al., 2003a) in an underpopulated plasma sheet (Kistler et al., 2005) with unusual ion velocity distributions (Wilber et al., 2004). The important result is that only in two cases (19 and 24) as the current density distributed from $-B_{L}$ to $+B_{L}$ have a profile resembling the Harris function. In both cases the current was very strong $\left(\sim 25\right.$ and $\sim 20 \mathrm{nA} / \mathrm{m}^{2}$, respectively) and the ion density was small (of $0.2 \mathrm{~cm}^{-3}$ ).

The average profile of the class I central sheet (Fig. 4 upper panel) is characterized by a layer between $\left|Z^{*}\right| \leq 2000 \mathrm{~km}$, with peak at $B_{l} \sim 0$, where the magnetic field gradient is larger than outside. In terms of the characteristic proton length, with a median value of $300 \mathrm{~km}$, the half-thickness of the central layer is about 5-7 $L_{c p}\left(L_{c p}\right.$ is the asymptotic gyroradius, calculated with the average proton temperature and the estimated lobe magnetic field). The current density outside this layer forms the "shoulders" at about $2 \mathrm{nA} / \mathrm{m}^{2}$. Because the current in the class I current sheets is concentrated in the embedded layer between roughly $\pm 0.5 B_{L}$, it cannot be described by the Harris function with the lobe field, calculated from the pressure balance, and used as a parameter. A more adequate fit can be done using the asymptotic magnetic field value $B_{0}\left(<B_{L}\right)$ instead of $B_{L}$ in Eqs. (1) and (2). Here we used as $B_{0}$ the value of $B_{l}$, where the current density drops down by a factor of 0.25 from the maximum to estimate $B_{0}$. Corresponding values of the Harris scale $\lambda^{\prime}$ for the class I sheets are also given in Table 3.

Figure 5 shows profiles of the current density (normalized by its maximum value), proton density and temperature (normalized by their values at the sheet center, $N p_{0}$ and $T p_{0}$, respectively) and the sum of the magnetic and ion pressures $\left(P t_{i}=B^{2} /\left(2 \mu_{0}\right)+P_{i}\right.$, where $\left.P_{i}=P_{H^{+}}+P_{O^{+}}\right)$, normalized by their maximum value, versus the $l$-component of the magnetic field (normalized by the lobe magnetic field value $B_{L}$ ), for the class I current sheet crossings. To see the temporal changes we adjust the sign of $B_{l}$ so that all crossings start from the northern half. To select the central plasma sheet samples only the CIS-CODIF data from Cluster 1 and 4 were used for samples with the proton- $\beta>0.5$ (Angelopoulos et al., 1994). The average current density profile has its maximum at $B_{l}=0$, the current density decreases to $\sim 0.3$ of the maximum value when $B_{l} \sim 0.4 B_{L}$. Both proton density and temperature show a decrease of $10 \%$ (in the northern half) from the central values at $B_{l} / B_{L}=0.5$, and, therefore, are close to being uniform within this layer of enhanced current, which is distinct from the Harris distribution. $P t_{i}$ is roughly equal at $B_{l}= \pm 0.5 B_{L}$ and decreases (up to 0.7 ) around $B_{l}=0$.

The average profile of the class II (bifurcated) current sheets is shown in Fig. 4, mid panel. The scale of the entire structure is about $4000 \mathrm{~km}$ or $\sim 10 L_{c p}$. The half-thickness of the individual peaks (based on its outer slope), as well as the width of the minimum in between, is $\leq 2000 \mathrm{~km} \sim 5 L_{c p}$. Profiles of normalized current density, proton density, temperature and total pressure versus $B_{l} / B_{L}$ are shown in Fig. 6 . Again proton density and temperature have almost uniform flat profiles. The sum of the magnetic and ion pressures $P t_{i}$ has a broad minimum between $\left|B_{l}\right| \leq 0.5 B_{L}$, decreasing up to 0.6 of the maximum value, and roughly the same values at $\left|B_{l}\right|>0.5 B_{L}$. Note that class-II includes the only highspeed event (\#20, 1 Oct. 2001), when the current sheet bifurcation was due to reconnection (Runov et al., 2003a) and the plasma sheet pressure was dominated by $\mathrm{O}^{+}$ions (Kistler et al., 2005). The scale parameters $h$, specified in Table 3 , for the class II current sheets are the estimate of the entire structure half-thickness (with respect to $B_{l}=0$ ). 

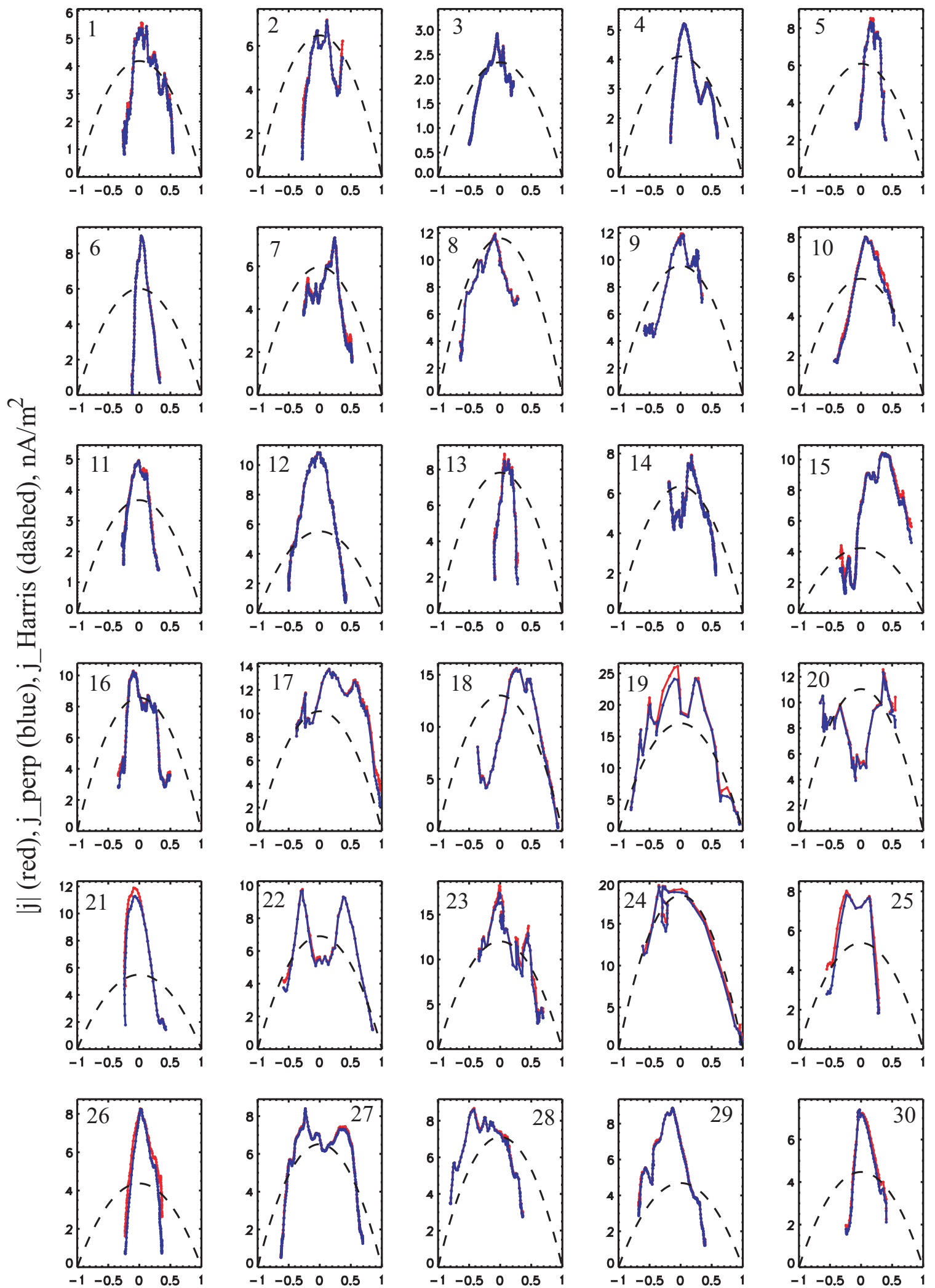

Bl_bc/BL

Fig. 2. Hodograms of the current density $\boldsymbol{j}=\mu_{0}^{-1} \nabla \times \boldsymbol{B}$ absolute value (blue) and perpendicular component $j_{\perp}=\sqrt{j_{m}^{2}+j_{n}^{2}}$ (red) versus main magnetic field $\left(B_{l}\right)$ for selected 30 cases. Dashed lines show the Harris function, Eq. (1), with the parameter $\lambda$ calculated using an average magnetic field gradient. 

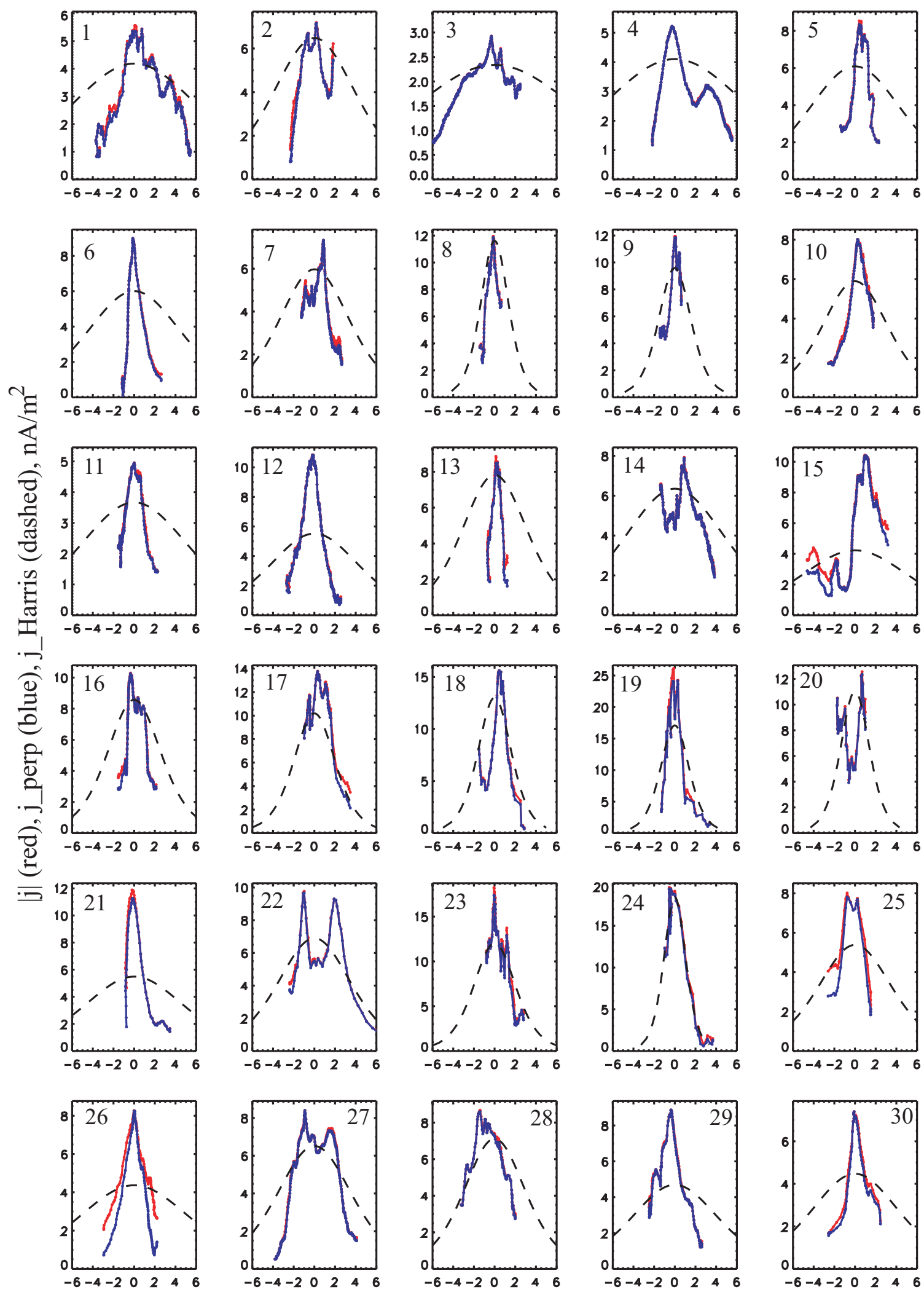

$Z^{*}, \mathrm{Z}$ Harris, $1000 \mathrm{~km}$

Fig. 3. Profiles of absolute values of the current densities $j$ (blue) and $j_{\perp}$ (red) versus the effective vertical coordinate $Z^{*}$, calculated from Eq. (3). Dashed lines show the corresponding Harris profiles. 

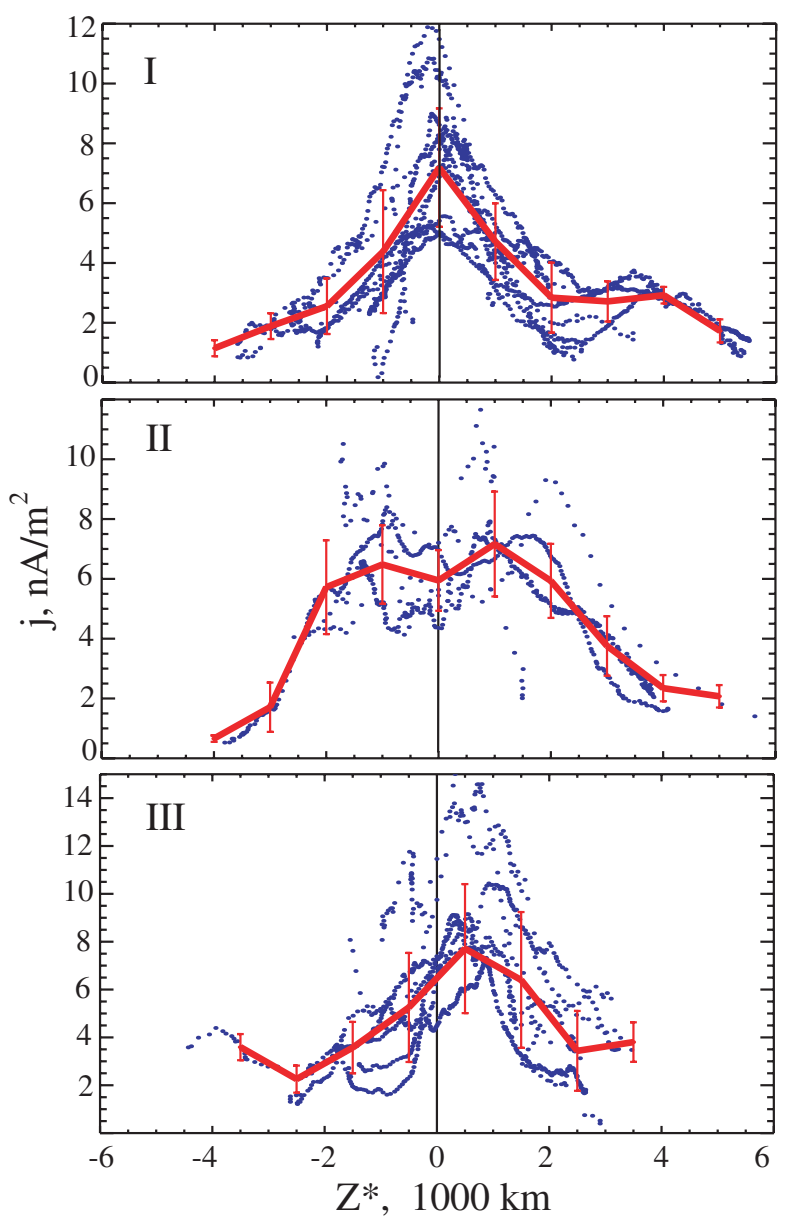

Fig. 4. Averaged vertical profiles of the current density for center peaked (class I), bifurcated (class II), and asymmetric (class III) current sheets. The $\mathrm{Z}^{*}$ is calculated using Eq. (3).

To show the class III current sheets with peaks above and below the neutral sheet on the same plot, we changed the signs of $Z^{*}$ and $B_{l}$ in the events with peaks below the neutral sheet, so that these peaks will appear at $B_{x}>0$ in Fig. 7 . Off-center current sheets have a scale of $\leq 2000 \mathrm{~km}$ and an asymmetric profile, so that the half-thickness at the outer side is smaller $(\leq 1500 \mathrm{~km})$ than at the inner side $(\geq 2000 \mathrm{~km})$. The current density peaks were found at $0.2<B_{l} / B_{L}<0.6$. As in the previous cases, only samples with a corresponding proton $\beta<0.5$ are used to plot the proton parameters. The density has a flat profile at $B_{l}<0.5 B_{L}$ and drops at $B_{l} / B_{L}>0.5$. The temperature profile has a broad maximum around $B_{l}=0$. The $P t_{i}$ has a slightly asymmetric profile with a maximum at $B_{l} \sim 0.5 B_{L}$, a broad minimum between $-0.5<B_{l} / B_{L} \leq 0.3$, and with a value at $B_{l} \leq-0.5 B_{L}$ which is about 0.7 of the maximum value. Scales $h$ (Table 3 ) for the class III sheets are estimated as a half-thickness at the level of $j=0.5 j_{\max }$. These estimates, as well as $h$ for classes I and II are very rough and are rounded off to $500 \mathrm{~km}$.

Figure 8 shows an example of the asymmetric off-center current sheet. Here we present $10 \mathrm{~min}$ of Cluster/FGM data

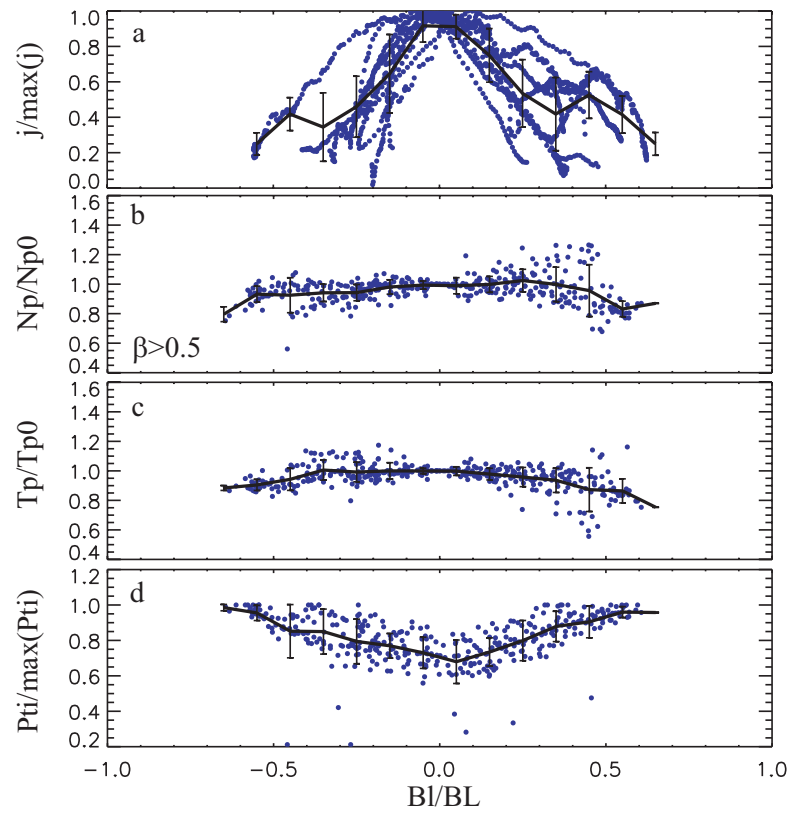

Fig. 5. Profiles of the current density (a), proton number density, normalized by the value $N_{0}=N_{p}\left(B_{l}=0\right)$ (b), and proton temperature (c) normalized by $T_{0}=T_{p}\left(B_{l}=0\right)$, and the sum of magnetic and ion pressures $\left(P t_{i}\right)(\mathbf{d})$, normalized by their maximum value, versus normalized main magnetic field $B_{l} / B_{L}$ for class I current sheets.

on 24 September 2001, starting at 08:04:20 UT ( $\mathrm{t}=0$ ). Cluster crosses the neutral sheet twice (crossings 15 and 16 in Table 1). Panel (a) shows the projections of the electric current vector onto the $Y-Z$ plane and the positions of the Cluster spacecraft with respect to the barycenter. This event is similar to the one discussed by Runov et al. (2005a). Cluster observes a fold of the current sheet, traveling duskward with a velocity of $\sim 25 \mathrm{~km} / \mathrm{s}$. The electric current at the fronts of the fold is directed almost vertically, downward at the leading front (100-200s) and upward at the second front (380$500 \mathrm{~s})$. At the leading front the current density maximum is achieved at around $\mathrm{t}=150 \mathrm{~s}$, when the average magnetic field is $\sim 15 \mathrm{nT}$. The current density decreases by a factor of 2 at the neutral sheet. Between 210 and $380 \mathrm{~s}$ the spacecraft stay at $-10<B_{x}<0 \mathrm{nT}$. The current density here is three times smaller than at the leading front. At the next front the current density increases again. At this time the current sheet seems to be slightly bifurcated. Interestingly, the kink structure is associated with an enhancement of the $Z_{G S M}$ component of the magnetic field which is current sheet aligned at the fronts, but the $B_{y_{G S M}}$ component, which is approximately normal to the fronts, remains very small $(<1 \mathrm{nT})$. This example shows that the current density can change during the passage of perturbation, increasing at its fronts.

The important quantities, characterizing structure and geometry of the current sheet, are summarized in Table 3. Here we specify the current sheet types (I, II, or III, with a question mark in cases when the class definition is not clear), the half-thicknesses $h$, estimated from $j\left(Z^{*}\right)$ profiles 
Table 3. Current sheet parameters.

\begin{tabular}{|c|c|c|c|c|c|c|c|c|c|c|c|}
\hline $\mathrm{N}$ & type $^{\mathrm{a}}$ & $h^{\mathrm{b}}$ & $\lambda^{\mathrm{c}}\left(\lambda^{\prime}\right)$ & $B_{m}{ }^{\mathrm{d}}, \mathrm{nT}$ & $B_{n}^{\mathrm{d}}, \mathrm{nT}$ & $\sigma B / B_{N S}{ }^{\mathrm{e}}$ & $R_{c \min }^{\mathrm{f}}$ & $L_{c p}{ }^{\mathrm{g}}$ & $L_{i p}{ }^{\mathrm{g}}$ & $\rho_{p t h} \mathrm{~h}$ & $\kappa^{\mathrm{i}}$ \\
\hline 1 & $\mathrm{I}(?)$ & 3.0 & 8.8 & 9.5 & 2.2 & 0.014 & 5.4 & 0.303 & 0.287 & 1.13 & 2.2 \\
\hline 2 & I/II & 2.0 & 5.2 & -5.4 & 1.3 & 0.019 & 1.8 & 0.317 & 0.297 & 1.63 & 1.1 \\
\hline 3 & $\mathrm{I}(?)$ & 4.0 & 11.1 & 0.1 & 1.3 & 0.012 & 0.4 & 0.501 & 0.433 & 6.52 & 0.2 \\
\hline 4 & I & 2.0 & $9.7(3.3)$ & -13.1 & 3.3 & 0.003 & 6.9 & 0.325 & 0.307 & 0.900 & 2.8 \\
\hline 5 & III & 1.5 & 6.2 & 8.0 & 4.7 & 0.023 & 2.4 & 0.176 & 0.174 & 0.690 & 1.8 \\
\hline 6 & I & 1.0 & $6.3(0.9)$ & -7.0 & 1.7 & 0.016 & 1.6 & 0.184 & 0.177 & 0.782 & 1.4 \\
\hline 7 & III & 1.5 & 4.6 & 1.3 & 0.5 & 0.026 & 0.4 & 0.422 & 0.377 & 8.07 & 0.2 \\
\hline 8 & I & 1.0 & 1.8 & -0.6 & 0.6 & 0.051 & 0.1 & 0.268 & 0.271 & 6.37 & 0.1 \\
\hline 9 & I & 1.0 & 2.1 & -0.1 & 0.3 & 0.028 & 0.2 & 0.253 & 0.265 & 4.73 & 0.2 \\
\hline 10 & I & 1.5 & $4.3(0.9)$ & 5.7 & 0.7 & 0.014 & 5.8 & 0.383 & 0.377 & 1.69 & 1.8 \\
\hline 11 & I & 2.0 & $6.7(1.7)$ & 6.3 & 0.2 & 0.013 & 5.6 & 0.389 & 0.377 & 1.63 & 1.8 \\
\hline 12 & I & 2.0 & $5.9(1.5)$ & 7.0 & -1.6 & 0.017 & 2.7 & 0.143 & 0.151 & 0.621 & 2.0 \\
\hline 13 & I & 1.0 & $4.2(2.2)$ & 6.8 & 1.9 & 0.028 & 1.6 & 0.147 & 0.148 & 0.648 & 1.5 \\
\hline 14 & II & 3.5 & 6.7 & -1.3 & 1.0 & 0.037 & 0.4 & 0.127 & 0.129 & 3.24 & 0.3 \\
\hline 15 & III & 2.5 & 7.1 & -1.8 & 0.6 & 0.055 & 0.4 & 0.247 & 0.279 & 2.41 & 0.4 \\
\hline 16 & III & 1.5 & 3.5 & 3.2 & 0.1 & 0.023 & 1.0 & 0.241 & 0.276 & 2.24 & 0.7 \\
\hline 17 & III & 2.0 & 2.6 & 0.2 & 0.4 & 0.12 & 0.3 & 0.242 & 0.226 & 6.38 & 0.2 \\
\hline 18 & III & 2.5 & 2.1 & 2.4 & -0.5 & 0.071 & 1.2 & 0.231 & 0.225 & 2.50 & 0.7 \\
\hline 19 & $\mathrm{I}(?)$ & 1.0 & 1.8 & -4.1 & 4.5 & 0.25 & 0.3 & 0.298 & 0.510 & 1.56 & 0.4 \\
\hline 20 & II & 2.5 & 1.9 & -0.9 & 4.8 & 0.19 & 0.7 & 0.702 & 3.252 & 2.67 & 0.5 \\
\hline 21 & I & 1.5 & $6.5(0.9)$ & -1.9 & 1.2 & 0.044 & 0.5 & 0.330 & 0.304 & 5.28 & 0.3 \\
\hline 22 & II & 4.5 & 4.7 & 1.1 & 0.4 & 0.12 & 0.7 & 0.281 & 0.351 & 5.58 & 0.4 \\
\hline 23 & $\mathrm{I}(?)$ & 1.0 & 2.7 & 3.5 & -0.9 & 0.10 & 0.2 & 0.337 & 0.379 & 3.07 & 0.3 \\
\hline 24 & I & 2.0 & 1.4 & 2.2 & 0.3 & 0.16 & 0.9 & 0.456 & 0.589 & 5.28 & 0.4 \\
\hline 25 & II & 2.5 & 4.8 & -2.2 & 3.1 & 0.085 & 1.1 & 0.463 & 0.423 & 2.26 & 0.7 \\
\hline 26 & I & 2.5 & $7.4(2.3)$ & 2.3 & 2.1 & 0.019 & 0.4 & 0.299 & 0.299 & 3.11 & 0.4 \\
\hline 27 & II & 4.5 & 4.9 & 3.6 & 0.8 & 0.020 & 2.0 & 0.269 & 0.320 & 2.35 & 0.9 \\
\hline 28 & III & 4.5 & 3.9 & 2.2 & 1.1 & 0.039 & 2.4 & 0.294 & 0.342 & 1.87 & 1.1 \\
\hline 29 & III & 2.0 & 5.7 & -0.7 & 1.3 & 0.027 & 0.2 & 0.302 & 0.337 & 5.56 & 0.2 \\
\hline 30 & I & 1.5 & $5.8(2.7)$ & -1.9 & 0.7 & 0.046 & 0.6 & 0.317 & 0.317 & 3.39 & 0.4 \\
\hline
\end{tabular}

a) I- central peaked, II- bifurcated, III- asymmetric;

b) half-thickness estimates, $1000 \mathrm{~km}$;

c) Harris scale parameter estimates (see details in the text), $1000 \mathrm{~km}$;

d) average values of current-align $\left(B_{m}\right)$ and normal $\left(B_{n}\right)$ components of the magnetic field in the neutral sheet $\left(\left|B_{l}\right| \leq 5 \mathrm{nT}\right)$;

e) the standard deviation of the magnetic field during the crossing, normalized by the average magnetic field in the neutral sheet;

f) the magnetic field curvature radius minimum value, $1000 \mathrm{~km}$;

g) characteristic scales: The asymptotic proton gyroradius $\left(L_{c}\right)$ and the ion inertial scale $\left(L_{i}\right), 1000 \mathrm{~km}$;

h) the proton thermal gyroradius in the neutral sheet, $1000 \mathrm{~km}$;

i) the adiabaticity parameter $\kappa=\sqrt{R_{c m i n} / \rho_{p_{t h}}}$.

(Fig. 3), parameters $\lambda\left(\lambda^{\prime}\right)$ of the corresponding Harris functions, Eq. (1). They are followed by current aligned $(m)$ and normal $(n)$ magnetic field components in the neutral sheet $\left(\left|B_{l}\right|<5 \mathrm{nT}\right.$ ), variability of the magnetic field $\sigma B$ (calculated as the standard deviation within 8-s (2-spin) long intervals, normalized by the mean value of the magnetic field in the neutral sheet) and minimum magnetic field curvature radii $R_{c m i n}$. The characteristic plasma scales include: asymptotic proton gyroradius $L_{c p}[1000 \mathrm{~km}]=4.6 \sqrt{T_{i}[\mathrm{keV}]} / B_{L}[\mathrm{nT}]$ and proton inertial length $L_{i p}[1000 \mathrm{~km}]=0.23 / \sqrt{N_{i}\left[\mathrm{~cm}^{-3}\right]}$. We also specified values for the proton thermal gyroradius $\rho_{p_{t h}}$ in the neutral sheet (in $1000 \mathrm{~km}$ ) and the corresponding values for the adiabaticity parameter $\kappa=\sqrt{R_{c \min } / \rho_{p_{t h}}}$ (Büchner and Zelenyi, 1989). Because the minima of the magnetic field curvature radius were found within the neutral sheet in all cases, the above-written $\kappa$-parameter definition was used for bifurcated sheets, too (theoretically, the $\kappa$-parameter has a special definition for double-peaked current sheets; Delcourt et al., 2004).

\section{Curlometer current versus proton contribution}

To compare the curlometer-based current $j_{c}$ with the proton contribution to the electric current, we calculate the current carried by the protons $j_{p}\left[\mathrm{nA} / \mathrm{m}^{2}\right]=0.16 N_{p} V_{p}$, using CISCODIF samples with $\beta_{p}=2 \mu_{0} N_{p} T_{p} / B^{2}>0.5$. Profiles of 


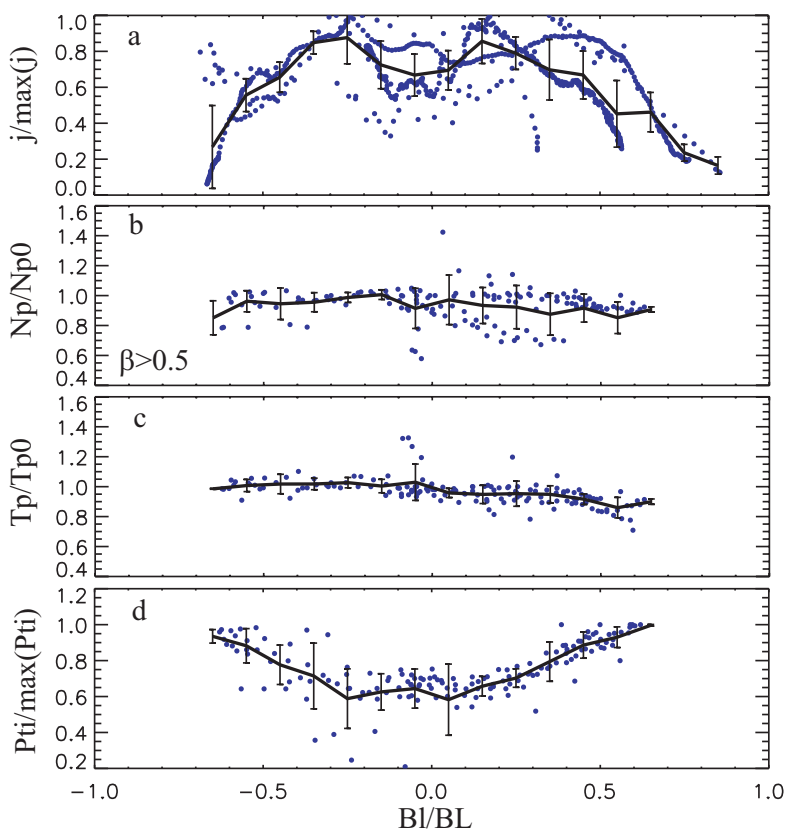

Fig. 6. Same as in Fig. 5 for class II current sheets.

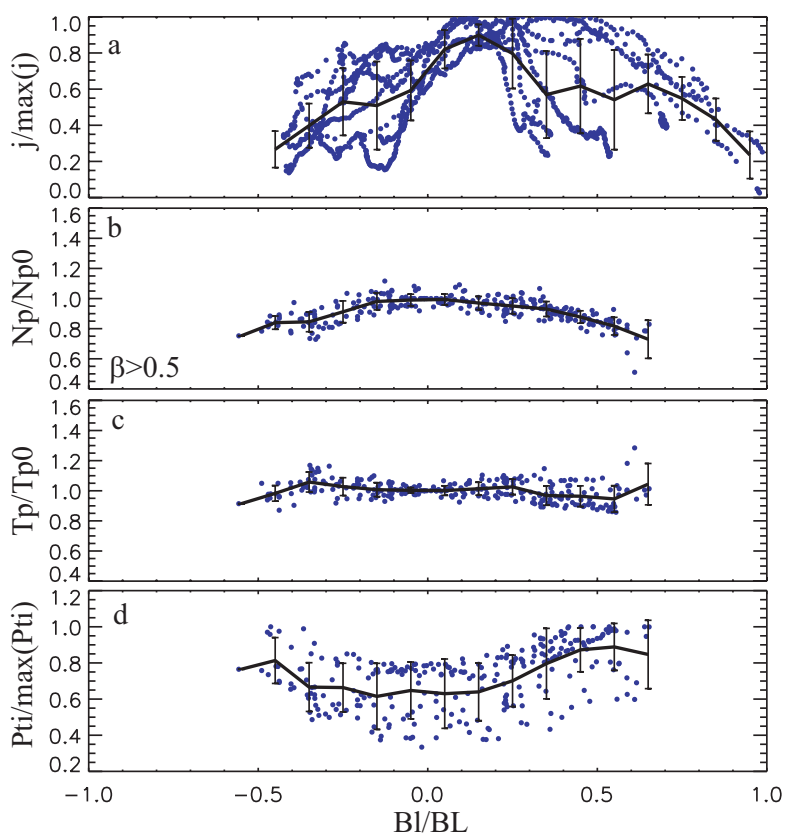

Fig. 7. Same as in Figs. 5 and 6 for class III current sheets.

$j_{c_{m}}$ and $j_{p_{m}}$ as functions of the normalized main magnetic field $B_{l} / B_{L}$ are shown in Fig. 9. It should be noted that because of the current sheet tilt in the $Y-Z$ plane (see Table 2), for a majority of crossings the current aligned proton velocity is contributed to by the $Z_{G S E}$ component, which is measured with a significant inaccuracy, possibly resulting in the $j_{p_{1}}$ and $j_{p_{4}}$ differences. The velocity offset of $20 \mathrm{~km} / \mathrm{s}$ with the density $0.8 \mathrm{~cm}^{-3}$ (the mean value of the density for the selected events, Table 1) gives $j_{p} \sim 3 \mathrm{nA} / \mathrm{m}^{2}$.
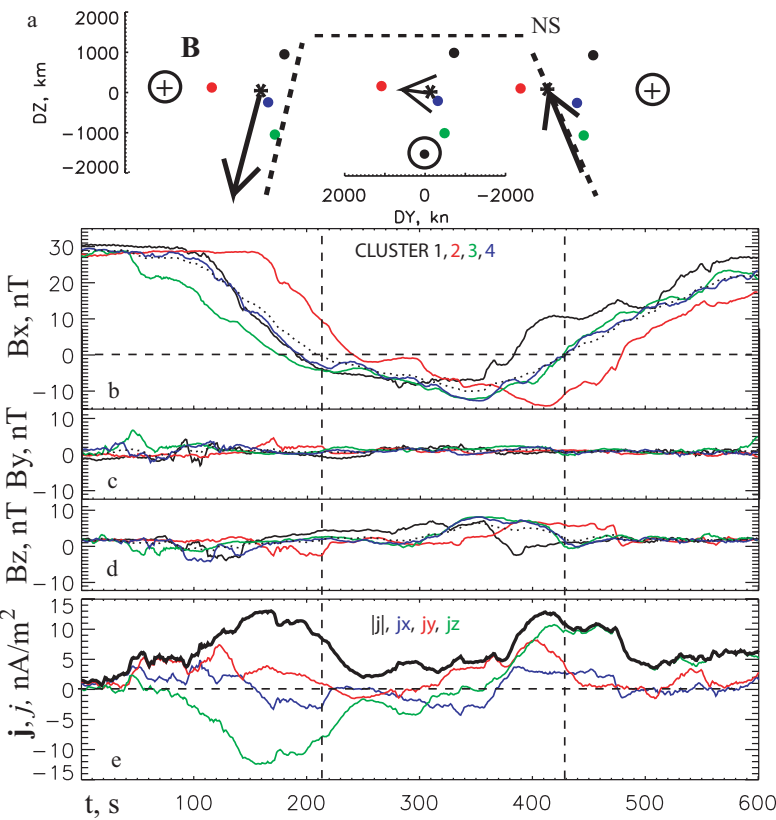

Fig. 8. Example of the class III current sheet: Cluster/FGM data (panels b-d), calculated current density (e) versus time (s). Panel (a) shows spacecraft separations and current vector projections on the $Y Z$ plane; barycenter positions are marked by asterisks; dashed lines display the shape of the current sheet kink.

The relationship between $j_{c}$ and $j_{p}$ appears to be complicated and variable. Both proton and curlometer currents have similar profiles and values in cases $1-6$ observed in the dawn sector. For the remaining cases observed mostly in the dusk sector, except for \# 22 (bifurcated profile), the proton current generally has an opposite sign (negative) and can even be much larger in magnitude (cases $14,17,18,23,28)$. This difference does not seem to depend on the type of the current sheet structure (I, II or III).

To characterize the difference quantitatively and to take into account the possible difference of cross-tail convection in the dawn and dusk plasma sheets, Fig. 10 shows the relative differences between the $m$-components of the proton current and the curlometer current $\left(\delta j=\left(j_{p}-j_{c}\right)_{m} / j_{c}\right)$, averaged in a $0.1 B_{L}$ layer within $\left|B_{l}\right|<0.5 B_{L}$ for each crossing. It varies in the dawn sector (upper panel, excluding the wild points) between -2 to 2 (with median value -0.46 and standard deviation about $300 \%$ ), and in the dusk sector (bottom panel) - from -4 to 2 (with median value -1.3 and standard deviation about $70 \%)$. Converting to the equivalent velocity $\left(V_{e}=\left(j_{p}-j_{c}\right) /\langle N\rangle\right.$, where $\langle N\rangle$ is the average proton density, tabulated in Table 1$)$, it gives a median velocity of about $-3 \mathrm{~km} / \mathrm{s}$ and $-24 \mathrm{~km} / \mathrm{s}$, correspondingly. Therefore, the equivalent velocity is preferentially directed dusk-to-dawn, with an amplitude in the dusk sector one order of magnitude higher than one in the dawn sector. 

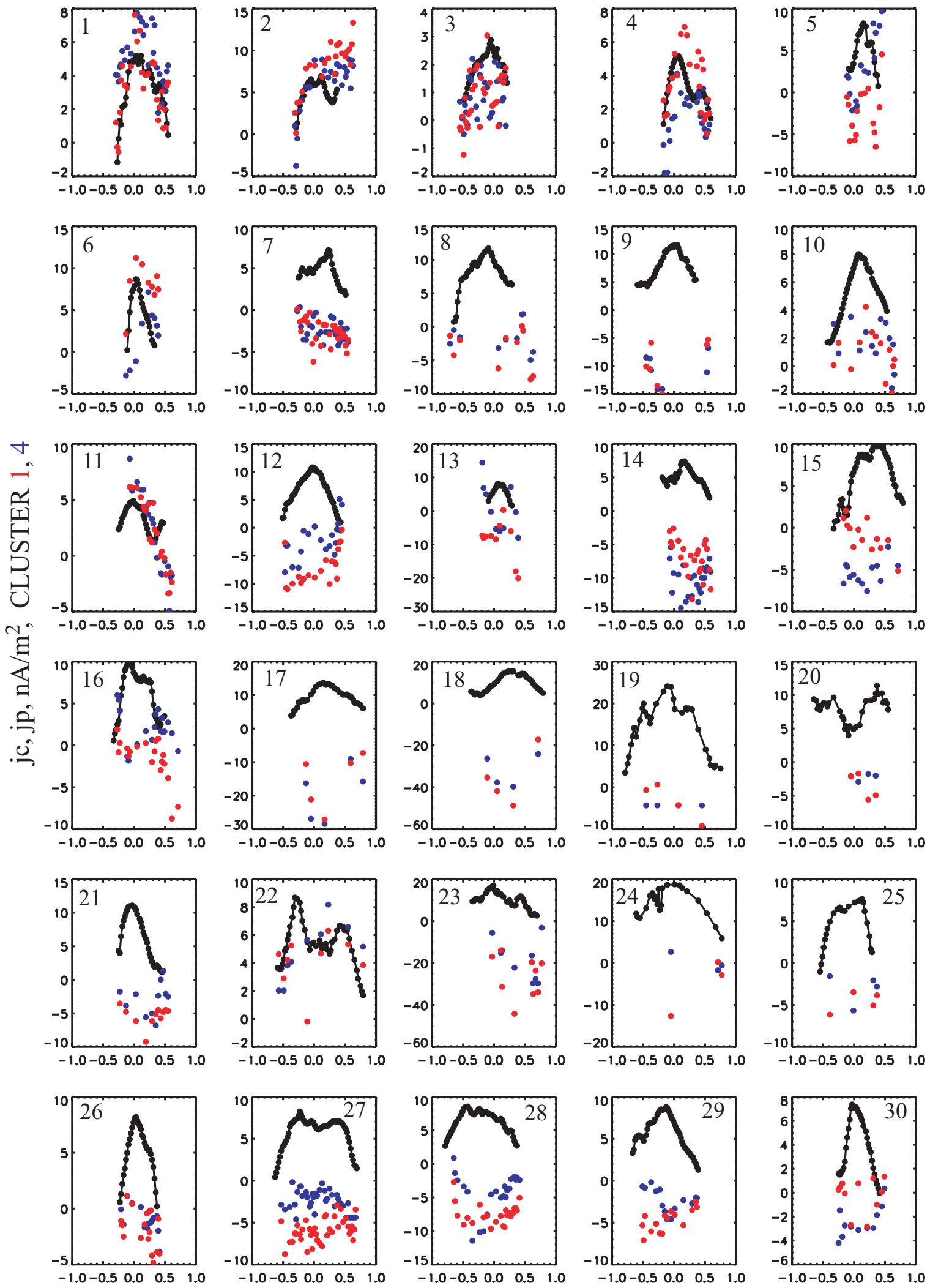

$\mathrm{Bl} \mathrm{bc} / \mathrm{BL}$

Fig. 9. Profiles of the curlometer current $m$-component (black) and the corresponding proton current $j_{p_{m}} \sim N_{p} V_{m}$ at Cluster 1 (red) and 4 (blue) versus $B_{l} / B_{L}$. 


\section{Discussion and conclusions}

We examined distributions of the electric current density, proton density, temperature and bulk velocity inside the magnetotail current sheet during 30 episodes of fast current sheet crossings by the Cluster spacecraft. Because the Cluster tetrahedron scale $a$ during July-October 2001 was $\sim 1500 \mathrm{~km}$, only structures with scales larger than $a$ were studied. By showing a variety of possible distributions we also found that the observed structures can be subdivided into three groups: central current sheets (I) with a sharp maximum of the current density at the neutral sheet; bifurcated current sheets (II) with two quasi-symmetric current density maxima in the northern and southern halves of the sheet and a minimum near the neutral sheet; and asymmetric off-center current sheets (III) with the current density maximum shifted away from the neutral sheet. Typical half-thicknesses of the current sheets are $\leq 2000 \mathrm{~km}$ or $\sim 5 L_{c p}$ for the classes I and III, and about $4000 \mathrm{~km}\left(\sim 10 L_{c p}\right)$ for class II. Profiles of the class III sheets are asymmetric with respect to the current density maximum. The large variety of current density distributions observed is consistent with the results by Asano et al. (2005), who used another technique (comparison of $B_{x}$ components observed at two pairs of Cluster spacecraft) and a different event selection (in particular, excluding time varying and strongly tilted sheets). Such a variable appearance, therefore, can be the rule for the magnetotail current sheet.

In agreement with Asano et al. (2005) we found strong deviations from the behavior predicted by the Harris model and, in fact, the non-Harris sheets can be the rule rather than the exception, for active current sheets in the magnetotail (see also Thompson et al., 2005). For example, the center-peaked current sheet (type I) profiles, except for two cases, 19 and 24, strongly differ from the Harris function: the current density is concentrated in the layer within $\pm 0.5 B_{L}$, where $B_{L}$ is the lobe field strength, calculated from pressure balance. Moreover, the proton density and temperature behave fairly uniform inside all types of current sheets, indicating that current density peak(s) are not simply followed by the plasma pressure variations and that they are embedded into more thicker plasma sheets.

The fact that the sum of the magnetic and ion pressures for I and II types of sheets has roughly the same values at both sides of the sheets and drops at the sheet center indicates that the total pressure is nearly conserved in these types of current sheets, and contributions from electrons (up to $15 \%$, according to Baumjohann et al., 1989) and ions with energies exceeding $38 \mathrm{keV}$ (not counted by CODIF) can be up to $30 \%$ of the aggregate $\mathrm{H}^{+}$and $\mathrm{O}^{+}$pressure in the sheet center (see also Fairfield et al., 1981). Contributions of $\mathrm{O}^{+}$ion pressure vary between $5-50 \%$ (see Table 1). The asymmetry of the proton total pressure profile in the class-III current sheets points out their transient nature.

In 16 out of the 30 studied cases the tilt angle of the current sheet normal with respect to the $Z_{G S M}$ direction exceeds $45^{\circ}$. In 17 cases the tilt was dawnward $\left(n_{Y}<0, n_{Z}>0\right)$ and duskward in 13 cases (Table 2). No definite correspondence
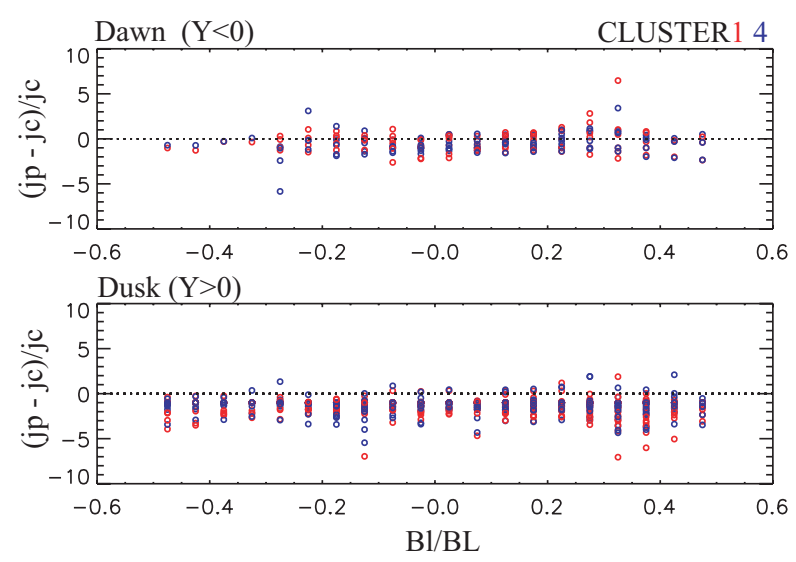

Fig. 10. Differences of proton $\left(j_{p}\right)$ and curlometer $\left(j_{c}\right)$ currents along the $m$ direction in the morning (a) and evening (b) sectors, normalized by the absolute value of the curlometer current.

between IMF $B_{y}$ and the normal tilt was found. The tilt of the current sheet in the studied cases indicates a corrugated profile of the sheet surface, crossed by the spacecraft during flapping.

In examining AE-activity dependence (Table 1) or local plasma conditions we could not find systematic differences between events with different types or different thicknesses of the current sheets in our limited survey. (More focused efforts with a larger database are required to reveal and quantify the activity dependence, if it exists at all.)

Nineteen (out of 30) cases represent low velocity intervals with $V<100 \mathrm{~km} / \mathrm{s}$. Two high-speed intervals (\# 19 and \# 20) were observed during a large substorm and show the complex structures, with most likely a single peak of current density (\# 19) and with a clearly bifurcated current sheet (\# 20). Ion densities and temperatures vary in a very broad range without any definite relation to the current sheet structures. Note that we have several examples of cold dense plasma sheets (\# 5, 6, 12-14) which show structures of all three types. The relative magnetic field variability ( $\sigma B$ in Table 3 ) was not big (generally less than 0.1 ) during the studied crossings, so we cannot attribute any differences in the structure of the current sheets to the effect of magnetic field fluctuations (e.g. Greco et al., 2002). The adiabaticity parameter $\kappa$ is generally less than unity, which indicates non-adiabatic ion motion within the flapping current sheets. Again, no simple relation with the current sheet structure can be observed.

Some theoretical studies of 1D thin and bifurcated current sheets (see, e.g. Sitnov et al., 2003, and references therein) suggest that the differences are mostly controlled by plasma anisotropy. More specifically, it was pointed out that even very small pressure anisotropy (of $\sim 10 \%$ ) can dramatically change the structure of the current sheet. The specific solutions of steady-state Vlasov equations with current density peaks away from the equatorial plane were found by Birn et al. (2004). Their model suggests a sufficient nongyrotropy inside a thin (comparable with the ion thermal 
gyroradius) current sheet. Bifurcated profiles of the current density can also result from a trapped ion population (Zelenyi et al., 2003) and from electrostatic effects (Zelenyi et al., 2004b) and the electron pressure anisotropy (see, e.g. Zelenyi et al., 2004a) in thin current sheets. In a preliminary study we surveyed the proton pressure anisotropy measured by the CIS instrument, but found that usually the anisotropy is very small (deviation from isotropy less than 10\%) with considerable scatter. Detailed studies of ion and electron distributions in the current sheet would require a special future effort, in particular, concentrating on the data in the highresolution instrument mode.

One source of the observed sheet variability and of nonHarris behavior could be temporal variations of the current density or the passage of localized (essentially non-1-D) current structures. In fact, the kink-perturbation, producing the flapping event in the current sheet, can carry localized asymmetric current structures. For example, in their PIC simulations, Karimabadi et al. (2003) have shown that the maximum of the current density is displaced from $B_{x}=0$ during the ion-ion kink instability excitation. Sitnov et al. (2004), simulating the evolution of a bifurcated current sheet, have found quasi-rectangular kinks of the sheet with asymmetric off-center (and grainy) current density distributions. This could be, in particular, a reason for observing the asymmetric (type III) current distributions. It is difficult to explore such effects with Cluster, which, for current measurements, acts as a 1-point instrument. Some information about this could be obtained after noticing that, if the peak current is due to localized enhanced current carried by the propagating kink, the position of $j_{\max }$ (say, in $B_{l} / B_{L}$ coordinates) will rather be defined by the location of spacecraft rather than by the $B_{l} / B_{L}$ coordinate itself. To check this we compared the position of the peak current with the location of the midpoint of each crossing for events in classes I and III. We have found that for central sheets (class I) the peak location has no relation to the spacecraft position, whereas for asymmetric current events (class III) some dependence, indicating a transient nature of the asymmetric sheets, is observed. The amount of the events is, however, small, and this test should be repeated on larger statistics.

The most intriguing (and potentially most interesting) observation is that, in most of cases, the proton contribution to the electric current is not the dominant contribution. The relative difference between the total (curlometer-based) current and proton contribution is several times larger than the total current, indicating that it is clearly the electrons which contribute to the tail current in the flapping events. (The contribution of oxygen ions is not large, $<20 \%$, even in storm-time oxygen-dominated plasma sheets according to Kistler et al., 2005.) The possible explanation of the observed difference should take into account that the contribution of each species is a sum of its magnetic and polarization drifts $\left(\boldsymbol{V}_{d}\right)$, producing an electric current, and electric $\left(\boldsymbol{V}_{c}\right)$ drifts, which does not produce the electric current (particularly $\boldsymbol{V}_{p}=\boldsymbol{V}_{d p}+\boldsymbol{V}_{c}$ for protons), Therefore, the difference between measured current density and the proton moment, shown in Fig. 10, is $\left(\boldsymbol{j}_{p}-\boldsymbol{j}_{c}\right) \simeq e N_{p}\left(\boldsymbol{V}_{c}-\boldsymbol{V}_{\mathrm{d}_{e}}\right)$ in the projection to the local direction of the current vector. The electric drift contribution $\left(\mathbf{V}_{c}\right)$ can be significant (even dominant) in the presence of a large normal electric field, directed toward the neutral sheet, producing dawnward convection. This electric field along the local sheet normal, converging to the neutral sheet center and suggesting a negative electric charge in the sheet center, should be of 0.5 to several $\mathrm{mv} / \mathrm{m}$, which is comparable to the average dawn-dusk electric field (e.g. Asano et al., 2004; Wygant et al., 2005). It can also be larger in the dusk sector, where the current sheet is generally more active (e.g. Nagai et al., 1998) than in the dawn sector. A clarification of the normal electric field contribution and an explanation of the observed dawn-dusk asymmetry are challenging issues for future studies which have to incorporate the measurements of electrons available at Cluster.

Acknowledgements. We wish to thank H.-U. Eichelberger, G. Laky, C. Mouikis, L. Kistler, E. Georgescu and E. Penou for help with data and software, M. Hoshino, L. Zelenyi, R. Treumann, A. Petrukovich, M. Sitnov, Ph. Louarn and H. Malova for fruitful discussion. ACE spacecraft data are provided by N. Ness (Bartol Research Institute) and available on CDAWeb. We thank WDC for Geomagnetism, Kyoto providing AE indices. This work is supported by INTAS 03-51-3738, by RFBR N 03-02-17533 and N 03-0520012 and by Russian Ministry of Education and Science (Intergeophysica) grants. The work by M. Volwerk was financially supported by the German Bundesministerium für Bildung und Forschung and the Zentrum für Luft- und Raumfahrt under contracts 50 OC 0104.

Topical Editor T. Pulkkinen thanks L. Zelenyi and another referee for their help in evaluating this paper.

\section{References}

Angelopoulos, V., Kennel, C. F., Coroniti, F. V., Pellat, R., Kivelson, M. G., Walker, R. J., Russell, C. T., Baumjohann, W., Feldman, W. C., and Gosling, J. T.: Statistical characteristics of bursty bulk flow events, J. Geophys. Res., 99, 21 257-21 280, 1994.

Asano, Y., Mukai, T., Hoshino, M., Saito, Y., Hayakawa, H., and Nagai, T.: Evolution of the thin current sheet in a substorm observed by Geotail, J. Geophys. Res., 108, 1189, doi:10.1029/2002JA009785, 2003.

Asano, Y., Mukai, T., Hoshino, M., Saito, Y., Hayakawa, H., and Nagai, T.: Statistical study of thin current sheet evolution around substorm onset, J. Geophys. Res., 109, A05 213, doi:10.1029/2004JA010413, 2004.

Asano, Y., Nakamura, R., Baumjohann, W., Runov, A., Vörös, Z., Volwerk, M., Zhang, T. L., Balogh, A., Klecker, B., and Rème, H.: How typical are atypical current sheets?, Geophys. Res. Lett., 32, L03 108, doi:10.1029/2004GL021834, 2005.

Balogh, A., Carr, C. M., Acuña, M. H., Dunlop, M. W., Beek, T. J., Brown, P., Fornacon, K.-H., Georgescu, E., Glassmeier, K.-H., Harris, J., Musmann, G., Oddy, T., and Schwingenschuh, K.: The Cluster magnetic field investigation: Overview of in-flight perfomance and initial results, Ann. Geophys., 19, 1207-1217, 2001,

SRef-ID: 1432-0576/ag/2001-19-1207. 
Baumjohann, W., Paschmann, G., Scopke, N., and Cattell, C. A.: Average plasma properties in the central plasma sheet, J. Geophys. Res., 94, 6597-6606, 1989.

Birn, J., Schindler, K., and Hesse, M.: Thin electron current sheets and their relation to auroral potentials, J. Geophys. Res., 109, A02 217, doi:10.1029/2003JA010303, 2004.

Büchner, J. and Zelenyi, L. M.: Regular and chaotic charged particle motion in magnetotaillike field reversals, 1, Basic theory of trapped motion, J. Geophys. Res., 94, 11 821-11 842, 1989.

Chanteur, G.: Spatial interpolation for four spacecraft: Theory, in: Analysis Methods for Multi-Spacecraft Data, edited by: Paschmann, G. and Daly, P., ESA, Noordwijk, 349-369, 1998.

Delcourt, D. C., Malova, H. V., and Zelenyi, L. M.: Dynamics of charged particles in bifurcated current sheets: The $\kappa \simeq 1$ regime, J. Geophys. Res., 109, A01 222, doi:10.1029/2003JA010167, 2004.

Fairfield, D. H., Hones Jr., E. W., and Meng, C.-I.: Multiple crossing of a very thin plasma sheet in the Earth's magnetotail, J. Geophys. Res., 86, 11 189-11 200, 1981.

Greco, A., Taktakishvili, A. L., Zimbardo, G., Veltri, P., and Zelenyi, L. M.: Ion dynamics in the near-Earth magnetotail: Magnetic turbulence versus normal component of the average magnetic field, J. Geophys. Res., 107, 1267, doi:10.1029/2002JA009270, 2002.

Harris, E. G.: On a plasma sheet separating regions of oppositely directed magnetic field, Nuovo Cimento, 23, 115-121, 1962.

Harvey, C. C.: Spatial gradients and volumetric tensor, in: Analysis Methods for Multi-Spacecraft Data, edited by: Paschmann, G. and Daly, P., 307-322, ESA, Noordwijk, 1998.

Hoshino, M., Nishida, A., Mukai, T., Saito, Y., Yamamoto, T., and Kokubun, S.: Structure of plasma sheet in magnetotail: Doublepeaked electric current sheet, J. Geophys. Res., 101, 24775 $24786,1996$.

Karimabadi, H., Pritchett, P. L., Daughton, W., and KraussVarban, D.: Ion-ion kink instability in the magnetotail: 2 Three-dimensional full particle and hybrid simulations and comparison with observations, J. Geophys. Res., 108, 1401, doi:10.1029/2003JA010109, 2003.

Kistler, L., Mouikis, C., Möbius, E., Klecker, B., Sauvaud, J.-A., Rème, H., Korth, A., Marocci, M. F., Lundin, R., Parks, G. K., and Balogh, A.: Contribution of nonadiabatic ions to the crosstail current and $\mathrm{O}^{+}$dominated thin current sheet, J. Geophys. Res., 110, A06 213, doi:10.1029/2004JA010653, 2005.

McComas, D. J., Russel, C. T., Elphic, R. C., and Bame, S. J.: The near-Earth cross-tail current sheet: Detailed ISEE 1 and 2 case studies, J. Geophys. Res., 91, 4287-4301, 1986.

Nagai, T., Fujimoto, M., Saito, Y., Machida, S., Terasawa, T., Nakamura, R., Yamamoto, T., Mukai, T., Nishida, A., and Kokubun, S.: Structure and dynamics of magnetic reconnection for substorm onsets with Geotail observations, J. Geophys. Res., 103, 4419-4440, 1998.

Nakamura, R., Baumjohann, W., Runov, A., Volwerk, M., Zhang, T. L., Klecker, B., Bogdanova, Y., Roux, A., Balogh, A., Rème, H., Sauvaud, J.-A., and Frey, H. U.: Fast flow during current sheet thinning, Geophys. Res. Lett., 29, 2140, doi:10.1029/2002GL016200, 2002.

Rème, H., Aostin, C., Bosqued, J. M., Danduras, I., Lavraud, B., Sauvaud, J.-A., Barthe, A., Bouyssou, J., Camus, T., Coeur-Joly, O., et al.: First multispacecraft ion measurements in and near the Earth's magnetosphere with the identical Cluster ion spectrometry (CIS) experiment, Ann. Geophys., 19, 1303-1354, 2001,

SRef-ID: 1432-0576/ag/2001-19-1303
Runov, A., Nakamura, R., Baumjohann, W., Treumann, R. A., Zhang, T. L., Volwerk, M., Vörös, Z., Balogh, A., Glassmeier, K.-H., Klecker, B., Rème, H., and Kistler, L.: Current sheet structure near magnetic X-line observed by Cluster, Geophys. Res. Lett., 30, 1579, doi:10.1029/2002GL016730, 2003a.

Runov, A., Nakamura, R., Baumjohann, W., Zhang, T. L., Volwerk, M., Eichelberger, H.-U., and Balogh, A.: Cluster observation of a bifurcated current sheet, Geophys. Res. Lett., 30, 1036 , doi:10.1029/2002GL016136, 2003b.

Runov, A., Sergeev, V. A., Baumjohann, W., Nakamura, R., Apatenkov, S., Asano, Y., Volwerk, M., Vörös, Z., Zhang, T. L., Petrukovich, A., Balogh, A., Sauvaud, J.-A., Klecker, B., and Rème, H.: Electric current and magnetic field geometry in flapping magnetotail current sheets, Ann. Geophys., 23, 1391-1403, 2005a,

SRef-ID: 1432-0576/ag/2005-23-1391.

Runov, A., Sergeev, V. A., Nakamura, R., Baumjohann, W., Zhang, T. L., Asano, Y., Volwerk, M., Vörös, Z., Balogh, A., and Rème, H.: Reconstruction of the magnetotail current sheet structure using multi-point Cluster measurements, Planet. Space Sci., 53, 237-243, 2005b.

Sanny, J., McPherron, R. L., Russel, C. T., Baker, D. N., Pulkkinen, T. I., and Nishida, A.: Growth-phase thinning of the near-Earth current sheet during CDAW 6 substorm, J. Geophys. Res., 99, 5805-5816, 1994.

Sergeev, V., Angelopulous, V., Carlson, C., and Sutcliffe, P.: Current sheet measurements within a flapping plasma sheet, J. Geophys. Res, 103, 9177-9188, 1998.

Sergeev, V., Runov, A., Baumjohann, W., Nakamura, R., Zhang, T. L., Volwerk, M., Balogh, A., Rème, H., Sauvaud, J.-A., André, M., and Klecker, B.: Current sheet flapping motion and structure observed by Cluster, Geophys. Res. Lett., 30, 1327, doi:10.1029/2002GL016 500, 2003.

Sergeev, V., Runov, A., Baumjohann, W., Nakamura, R., Zhang, T. L., Balogh, A., Louarn, P., Sauvaud, J.-A., and Rème, H.: Orientation and propagation of current sheet oscillations, Geophys. Res. Lett., 31, L05 807, doi:10.1029/2003GL019346, 2004.

Sergeev, V. A., Mitchell, D. G., Russell, C. T., and Williams, D. J.: Structure of the tail plasma/current sheet at $\sim 11 R_{E}$ and its changes in the course of a substorm, J. Geophys. Res, 98, 17345-17365, 1993

Sitnov, M. I., Guzdar, P. N., and Swisdak, M.: A model of the bifurcated current sheet, Geophys. Res. Lett., 30, 1712, doi:10.1029/2003GL017218, 2003.

Sitnov, M. I., Swisdak, M., Drake, J. F., Guzdar, P. N., and Rogers, B. N.: A model of the bifurcated current sheet: 2. Flapping motion, Geophys. Res. Lett., 31, L09 805, doi:10.1029/2004GL019473, 2004.

Thompson, S. M., Kivelson, M. G., Khurana, K. K., McPherron, R. L., Weygand, J. M., Balogh, A., Rème, H., and Kistler, L. M.: Dynamic Harris current sheet thickness from Cluster current density and plasma measurements, J. Geophys. Res., 110, A02 212, doi:10.1029/2004JA010714, 2005.

Wilber, M., Lee, E., Parks, G. K., Meziane, K., Carlson, C. W., McFadden, J. P., Rème, H., Dandouras, I., Sauvaud, J.-A., Bosqued, J.-M., Kistler, L., Möbius, E., McCarthy, M., Korth, A., Klecker, B., Bavassano-Cattaneo, M.-B., Lundin, R., and Lucek, E.: Cluster observations of velocity space-restricted ion distributions near the plasma sheet, Geophys. Res. Lett., 31, L24 802, doi:10.1029/2004GL020265, 2004.

Wygant, J. R., Cattell, C. A., Lysak, R., Song, Y., Dombeck, J., McFadden, J., Mozer, F. S., Carlson, C. W., Parks, G., Lucek, 
E. A., Balogh, A., Andre, M., Reme, H., Hesse, M., and Mouikis, C.: Cluster observations of an intense normal component of the electric field at a thin reconnecting current sheet in the tail and its role in the shock-like acceleration of the ion fluid into the separatrix region, J. Geophys. Res., 110, A09 206, doi:10.1029/2004JA010708, 2005.

Zelenyi, L. M., Malova, K. V., and Popov, V. Y.: Splitting of thin current sheets in the Earth's magnetosphere, JETP Letters, 78, 296-299, 2003.

Zelenyi, L. M., Malova, H. V., Popov, V. Y., Delcourt, D., and Sharma, A. S.: Nonlinear equilibrium structure of thin current sheets: Influence of electron pressure anisotropy, Nonlinear Processes Geophys., 11, 579-587, 2004a.

Zelenyi, L. M., Malova, H. V., Popov, V. Y., Delcourt, D., and Sharma, A. S.: Role of electrostatic effects in thin current sheets, in: Multiscale Processes in the Earth's Magnetosphere: From Interball to Cluster, edited by: Sauvaud, J.-A. and Němeček, Z., Kluwer Academic Publisher, Netherland, 275-288, 2004b. 